\title{
Sobre Corpos Dóceis e Conchas: Processos de Trabalho nas Oficinas de Meia-Máscara do Grupo Manjericão
}

About Docile Bodies and Shells: Work Processes at the Manjericão Group's Half Mask Workshops

Márcio Silveira dos Santos ${ }^{1}$ 


\section{Resumo}

O presente artigo aborda o trabalho desenvolvido nas oficinas de meiamáscara do Grupo Manjericão, de Porto Alegre - RS, com um recorte a partir das práticas de duas oficinas realizadas nas cidades de Manaus (AM) e Macapá (AP). Analiso as transformações ocorridas nestas oficinas tendo como mote questões levantadas por Maria Brígida de Miranda a respeito da docilização dos corpos nas práticas de formação do ator. Bem como teço reflexões sobre os processos disciplinares destas práticas, na perspectiva de Foucault, na constituição de um tipo específico de corpo; dócil!

Palavras-chave: Meia-máscara; Formação do ator; Corpos dóceis; Grupo Manjericão

\section{Abstract}

This article reflects on the work developed in the half mask workshops of the Manjericão Group, from Porto Alegre - RS, based on practices of two workshops held in the cities of Manaus (AM) and Macapá (AP). I analyze changes occurred in those workshops based on the questions raised by Maria Brígida de Miranda regarding the docilization of bodies in the practices of actor's formation. In addition, I reflect on the disciplinary process of those practices, in the Foucault perspective, in the constitution of a specific body type; docile!

Keywords: Half mask ; Actor formation; Docile bodies; Manjericão Group

ISSN: 1414.5731

E-ISSN: 2358.6958

${ }^{1}$ Doutorando no Programa de Pós-Graduação em Teatro (PPGT) - UDESC. Mestre em Artes Cênicas pelo PPGAC/UFRGS. Ator, diretor, dramaturgo, produtor, articulador da RBTR. marccioss@yahoo.com.br 


\section{Grupo Manjericão}

O Grupo Manjericão foi fundado em fevereiro do ano de 1998 na Cidade de Porto Alegre no Estado do Rio Grande do Sul, tendo por ideia central pesquisar e criar espetáculos para encenar na rua. No trabalho desenvolvido pelo grupo sempre houve a necessidade de refletir sobre o processo pedagógico de criação do ator, buscando ampliar a qualidade cênica no espaço citadino da rua. Para isso a máscara passou a ser um recurso fundamental na "desnaturalização do ator" como queria Jacques Copeau (2013) e na "dilatação da energia" do corpo, levantada por Eugênio Barba (1995). A máscara se tornou tão importante no trabalho que nestes quase 20 anos de Grupo Manjericão todos os espetáculos ${ }^{2}$ tiveram a sua presença de forma marcante, seja por meia-máscara, máscara inteira ou de acento (palhaço).

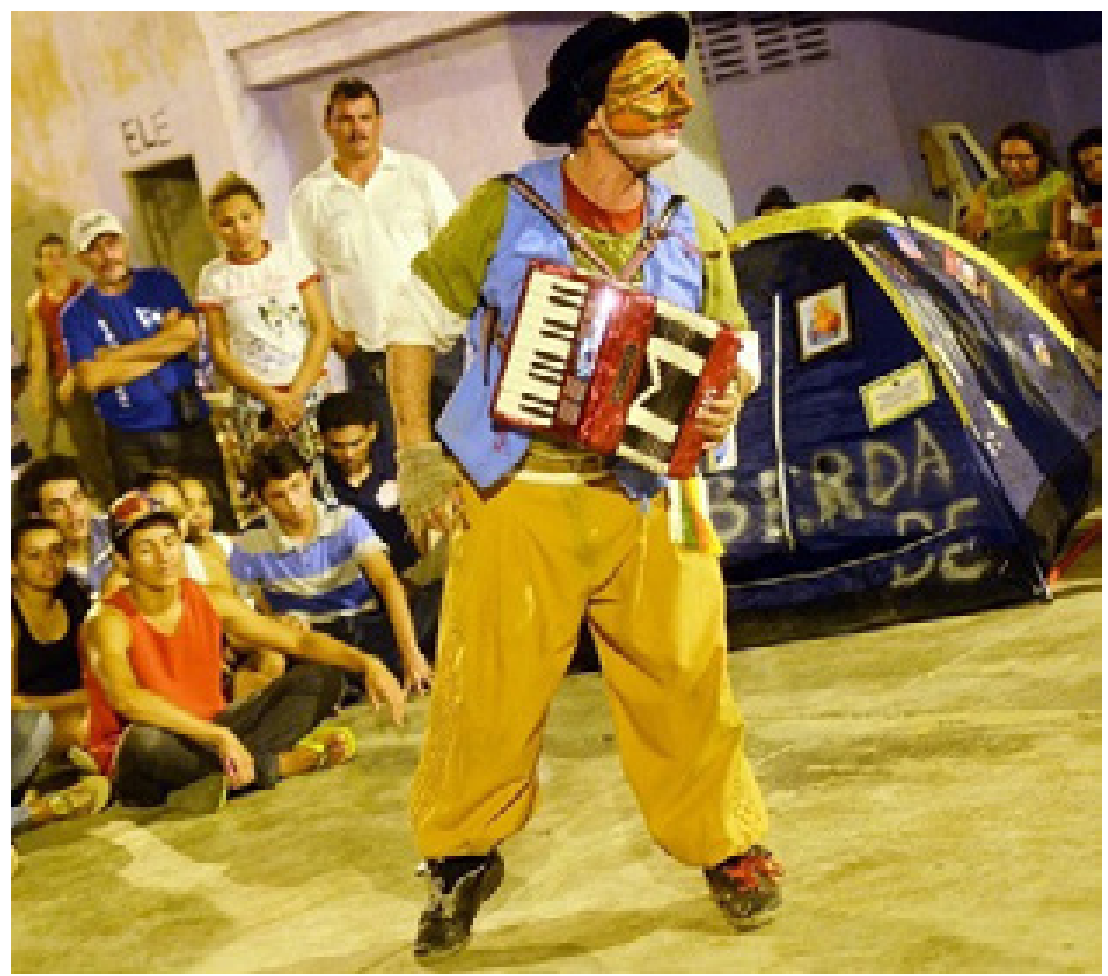

Espetáculo João Pé-de-Chinelo (2013). Ator e diretor: Márcio Silveira.

Grupo Manjericão (RS). Foto: Junio Santos

Dentro das estruturas de trabalho de grupos como o Manjericão, Ói Nóis Aqui Traveiz, De Pernas Pro Ar, Levanta Favela, UEBA Produtos Notáveis, entre outros grupos gaúchos que primam pelo teatro de rua em suas criações, encontra-se um potente manancial de práticas e procedimentos diferenciados, por se tratar de uma preparação outra para atuar no espaço da rua, diferenciado do preparo do ator para atuar na caixa cênica do teatro de palco italiano. Uma das diferenças, por exemplo, é a forma de atuação frontal no teatro de palco italiano e a atuação em ângulo de $360^{\circ}$, que geralmente ocorre no teatro de rua quando o espetáculo é encenado em forma de roda, exigindo do ator uma preparação de atuação que contemple toda a plateia no seu entorno. E nestes grupos, geralmente na esfera de desenvolvimento de

${ }^{2}$ Ver em: http://grupoteatralmanjericao.blogspot.com.br 
novos processos criativos, segundo Narciso Telles, "quase todos desenvolvem uma estrutura de treinamento, para o aperfeiçoamento de seus atores, e um conjunto de oficinas de formação/aperfeiçoamento de sua linguagem para outros artistas" (Telles, 2008, p. 33). Essas atividades "artístico-pedagógicas" caminham na direção daquilo que cada grupo deseja desenvolver em suas criações teatrais.

E no intuito de troca/compartilhamento dos processos de trabalho do Grupo Manjericão, passamos a ministrar oficinas de commedia dell'arte ${ }^{3}$ como proposta de formação de outros atores e atrizes por onde o grupo circular. Gênero que aprofundamos no trabalho com a meia-máscara. Seus elementos como o ritmo, a improvisação, o jogo e suas técnicas específicas de utilização da meia-máscara, são bases imprescindiveis para uma formação qualitativa para o trabalho de ator. Peter Brook em seu artigo "A máscara - saindo de nossas conchas" (Brook, 1994, p. 287) traz a ideia da máscara como uma "concha" onde o ator ao utilizá-la não tem mais o suporte de suas expressões faciais e corporais corriqueiras, passando a revelar outro corpo. A partir destas ideias definimos um conteúdo básico para as oficinas, que listo abaixo. ${ }^{4}$

- Introdução ao contexto histórico da commedia dell'arte.

- Preparação corporal para a commedia dell'arte, aquecimento, alongamento estudo e prática da corporeidade necessária aos personagens típicos. Técnicas do Grammelot $^{5}$, triangulação e Jograis ${ }^{6}$.

- Descrição e jogo cênico dos personagens clássicos da commedia dell'arte na postura e movimentos, com apreensão dos breves roteiros ${ }^{7}$ do repertório de Arlequim e Pantaleão.

- Utilização da meia-máscara da commedia dell'arte, (levadas pelo grupo) como introdução deste objeto cênico e experimentação na criação de uma linguagem capaz de estabelecer uma comunicação além da fala (como veremos no decorrer deste artigo).

\footnotetext{
${ }^{3}$ A Commedia dell'arte era, antigamente, denominada commedia all improviso, commedia a soggetto, commedia di zanni, ou, na França, comédia italiana, comédia das máscaras. Foi somente no século XVIII (segundo C. MIC, 1927) que essa forma teatral, existente desde meados do século XVI, passou a denominar-se Commedia dell'arte - a arte significando ao mesmo tempo arte, habilidade, técnica e o lado profissional dos comediantes, que sempre eram pessoas do ofício. Não se sabe ao certo se a Commedia dell'arte descende diretamente das farsas atelanas romanas ou do mimo antigo: pesquisas recentes puseram em dúvida a etimologia de Zanni (criado cômico) que se acreditava derivado de Sannio, bufão da atelana romana. Em contrapartida, parece ser verdade que tais formas populares, às quais se devem juntar os saltimbancos, malabaristas e bufões do Renascimento e das comédias populares e dialetais de RUZZANTE (1502 - 1542), prepararam o terreno para a commedia. (Pavis, 2008, p. 61).

${ }^{4}$ Este conteúdo se encontra nos materiais de divulgação das oficinas do Grupo Manjericão.

5 "Grammelot é uma palavra de origem francesa, inventada pelos cômicos dell'arte e italianizada pelos venezianos, que pronunciavam gramlotto. Apesar de não possuir um significado intrínseco, sua mistura de sons consegue sugerir o sentido do discurso. Trata-se, portanto, de um jogo onomatopeico, articulado com arbitrariedade, mas capaz de transmitir, com o acréscimo de gestos, ritmos e sonoridades particulares, um discurso completo" (Fo, 1998, p. 97).

6 "Os Jograis atuavam usualmente em primeira pessoa, um único ator sobre um palco - ou mesa - mesmo quando realizavam os contrastes ou os respetti, ou seja, diálogos de dois personagens. Aliás, a virtude particular de um jogral era exibir-se diante do público apresentando dezenas de personagens diferentes. Usavam o seu próprio e excêntrico traje, mas também não desdenhavam as caracterizações. Durante a realização de uma feira, por exemplo, subiam de improviso sobre um banco (origem provável da palavra "saltimbanco"), vestidos de esbirro, médico, advogado, padre, mercador, e começavam sua exibição a partir dai" (Fo, 1998, p.135).

${ }^{7}$ Os roteiros utilizados são roteiros criados pelo Grupo Manjericão a partir de roteiros do livro A Loucura de Isabella e outras Comédias da commedia dell'arte (Scala; Barni, 2003).
} 


\section{Corpos dóceis}

No ano de 2016, tivemos contato com a obra de Maria Brígida de Miranda (2003) na qual a autora levanta questões ligadas à docilização dos corpos nas práticas de formação do ator, tendo como base de reflexão a perspectiva de Foucault sobre as instituições disciplinares enquanto força produtiva, com suas "tecnologias disciplinares" na constituição de um tipo específico de corpo, dócil.

Segundo Foucault (1987, p. 163):

Houve, durante a época clássica, uma descoberta do corpo como objeto e alvo de poder. Encontraríamos facilmente sinais dessa grande atenção dedicada então ao corpo - ao corpo que se manipula, se modela, se treina, que obedece, responde, se torna hábil ou cujas forças se multiplicam. [...]. É dócil um corpo que pode ser submetido, que pode ser utilizado, que pode ser transformado e aperfeiçoado.

Miranda argumenta que através do surgimento de inovações e metodologias dos encenadores-diretores-pedagogos do teatro no século XX novas formas disciplinares de treinamento de ator ganharam força. Estabeleceu-se a busca de um corpo útil, de uma preparação física para determinados fins técnicos e de procedimentos de criação da nova cena que surgia.

A noção de "docilidade-utilidade" pode ser encontrada no discurso e na prática da maioria dos métodos de treinamento. Isto é evidente nas interações de três agrupamentos de corpos: os corpos dos atores, o corpo do conjunto, e o corpo do público. Manifestações destas novas interações podem ser vistas nas relações sociais entre os praticantes de teatro (por exemplo, o ator e o diretor, o ator e $o$ conjunto) com o público e na utilização do espaço. (Miranda, 2003, p. 64) ${ }^{8}$

O "Controle das atividades" é outro fator-elemento apontado por Miranda como parte dos "mecanismos disciplinares" no trabalho do ator. Principalmente no empenho corporal do ator no seu tempo de treinamento-ensaio. Encontramos uma série de formas de controle, do século XIX, no tempo dos métodos disciplinares monásticos, apontados por Foucault (1987) ao século XX, dos laboratórios, estúdios e oficinas, apontados por Miranda (2003). O "controle do corpo" também vai se expandir através dos novos métodos de formação e treinamento do ator.

A máscara também foi um elemento de controle por parte de muitos teatrólogos, cada um à sua maneira de pesquisar buscava outro sentido, ou um sentido a mais, no trato da preparação do ator que potencializasse a atuação. Segundo Miranda (2003, p. 71):

Muitos métodos de treinamento do ator, de Stanislavski em diante, são tentativas de melhorar a capacidade dos atores para manipular objetos e adereços. Esta articulação entre ator e objeto em última análise, visa a "absorção" do objeto pelo corpo do ator. Isto pode ser observado nos métodos de formação desenvolvido por Copeau, Decroux e Jacques Lecoq. As máscaras são os objetos mais importantes tratados por artistas nesta linhagem. Os rituais de interação entre o corpo

\footnotetext{
8 "No original: "The notion of "docility-utility" can be found in the discourse and practice of major training methods. This is evident in the interactions of three groupings of bodies: the bodies of the actors, the body of the ensemble, and the audience body. Manifestations of these new interactions can be seen in the social relationships between theatre makers (for example, the actor and the director, the actor and the ensemble) with the audience and in the use of space." (Tradução nossa).
} 
do ator e a máscara podem ser vistos como a codificação instrumental do corpo? .

Seguindo o raciocínio da docilização dos corpos e inserção das máscaras no trabalho de disciplina e treinamento dos grandes mestres do teatro, passo a refletir acerca de duas oficinas do Grupo Manjericão realizadas em Manaus (AM) e Macapá (AP) nos meses de março e maio de 2016 como parte da Circulação "Do Pampa Gaúcho à Floresta Amazônica" - Prêmio Funarte de Teatro Myriam Muniz 2014.

\section{As oficinas em Macapá e Manaus}

Passamos a experimentar novos processos de trabalho a partir de algumas indagações provocadas por Miranda, como por exemplo: que corpo é esse antes e depois da concha e em que nível de docilização estamos trabalhando? Que personagens outros derivam dos que trabalhamos? Quais jogos, ou qual a condução destes, podem torná-los mais libertários para os atores?

A partir dos tópicos do conteúdo das oficinas, colocados anteriormente aqui, passamos a desenvolver um processo de experimentação e mudanças nestas oficinas. Quanto à disciplina havia uma rigidez excessiva no desenvolvimento de certas práticas, como por exemplo, na preparação inicial do corpo do ator. Realizávamos um aquecimento-alongamento conduzido por uma pessoa do grupo sem nos darmos conta de que muitas vezes há uma diversidade grande de pessoas com idades e tipos diferentes de corpos, seja por alguma limitação física, sexo, função social, contexto, etc. Estabelecemos então um tempo inicial para cada aluno individualmente realizar um aquecimento-alongamento que sinta necessidade no seu corpo, para observarem qual parte do corpo esta pedindo mais atenção naquele momento. Foi uma mudança sutil, mas que produziu grande efeito no processo preparatório para o desafio do jogo com a "concha".

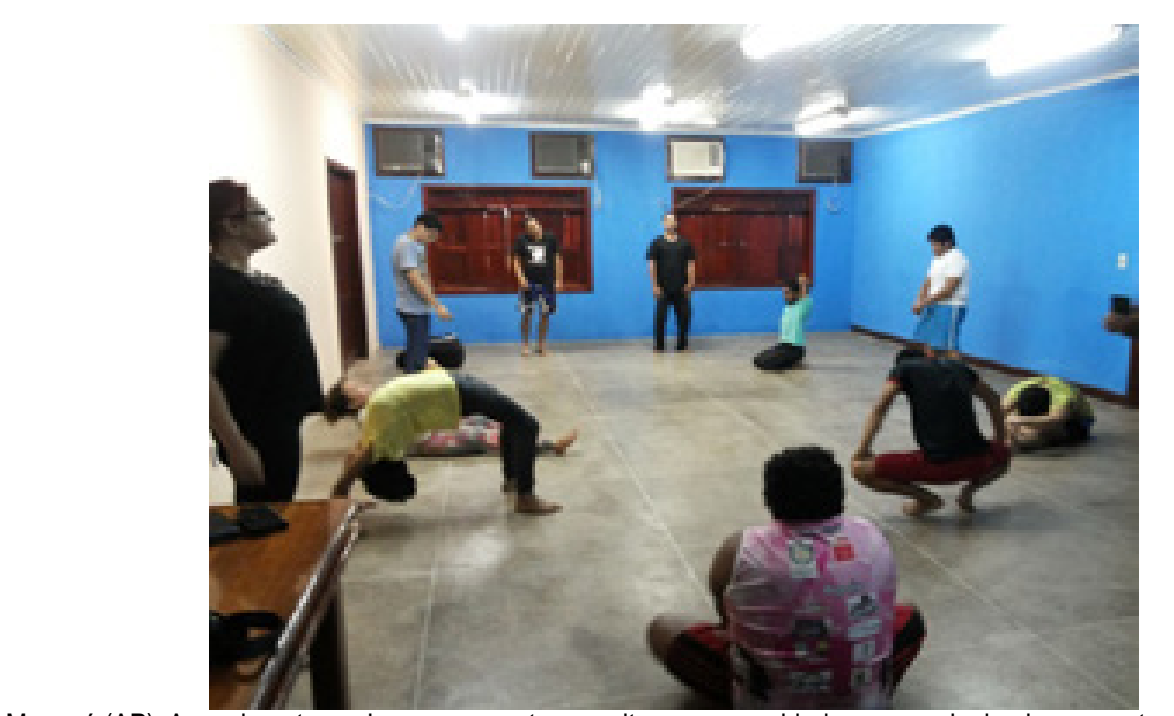

Macapá (AP): Aquecimento, cada um em seu tempo, ritmo e necessidades corporais de alongamento e aquecimento. Foto: Márcio Silveira (2016).

\footnotetext{
${ }^{9}$ No original: "Many actor training methods, from Stanislavsky onwards, attempt to improve the actors' ability to manipulate objects and props. This articulation between actor and object ultimately aims for the 'absorption' of the object by the actor's body. This can be observed in the training methods developed by Copeau, Decroux and Jacques Lecoq. Masks are the most important objects handled by performers in this lineage. The rituals of interaction between the actor's body and the mask can be seen as the instrumental coding of the body." (Tradução nossa).
} 
Nas oficinas por meio de jogos e exercícios procuramos um corpo "extracotidiano"10, que possibilite aos participantes, após vivenciar algumas técnicas da commedia dell'arte, criar novos tipos-personagens, ligados ao seu contexto regional. É necessário que todos estejam preparados para portar uma máscara, pois a máscara solicita ao seu portador um estado de jogo, de improviso que lhe proporcione vida, como nos afirma o pesquisador Felisberto Sabino da Costa (2005, p. 39):

Improvisar é da natureza da máscara, dado que o objeto deve, a cada dia, ser animado, receber o sopro divino - respiração - pelo ator para coloca-la e se colocar em movimento. Embora vá construindo um repertório, o ator não lhe tem apego e, a cada vez há o encontro entre ator e máscara, a (re)conhece, a (re)vê, a (re)cria.

Durante o jogo e as improvisações com a máscara, por meio de situações dadas pelos oficineiros a partir de roteiros (canovacci) de cenas da commedia dell'arte, aos poucos é constituído um universo de novas cenas. Através das experimentações e contextualização dos tipos da commedia dell'arte os alunos passam a ter uma dimensão maior sobre a aplicação do uso da máscara no trabalho do ator. Passam a dominar aos poucos as nuances que técnicas proporcionam ao dar vida às máscaras-personagens. A máscara solicita um corpo de energia e força, que the dê vida em cena.

Neste caminho de reflexão, Eugênio Barba em A Arte Secreta do Ator, nos diz que a máscara, enquanto "rosto provisório", é uma possibilidade de dar ao rosto do ator uma dimensão extracotidiana. No entanto é um grande desafio dar vida à máscara.

\footnotetext{
Quando os atores colocam uma máscara, é como se seu corpo fosse subitamente decapitado. Eles desistem de todo movimento e expressão da musculatura facial. A extraordinária riqueza do rosto desaparece. Há uma tal resistência criada entre o rosto provisório (kamen em japonês) e o ator que essa conversão do rosto em algo aparentemente morto pode, de fato, fazer com que se pense em uma decapitação. Este é, na verdade, um dos maiores desafios do ator: transformar um objeto estático, imóvel, fixo, num perfil vivo e sugestivo. (Barba, 1995, p. 118)
}

O que nos faz lembrar novamente da reflexão de Peter Brook sobre o ator sair de suas "conchas". Na medida em que avança no empenho e no processo de criação portando uma máscara, aos poucos vai desvelando uma qualidade no seu trabalho corporal e num caminho de retroalimentação vai dando vida a esse objeto de expressão estática, por vezes parecendo aos olhos de quem vê que há vida na máscara, que suas expressões fixas realmente se movem.

Dentre outras mudanças significativas nas oficinas do Manjericão uma delas foi o trato com as vestimentas. Anteriormente exigíamos que todos portassem roupas pretas ou escuras ao máximo para dar destaque às máscaras, inclusive uma touca (feita de meia calça) que serve para anular o cabelo. Mas percebemos que estávamos apenas reproduzindo do que havíamos aprendido em anos de intercâmbio com outros grupos mascareiros. Após liberação das vestes a oficina passou a ter uma diversidade de Arlequins e Pantaleões como nunca tínhamos visto. Os cabelos soltos ou atados de formas diferentes propiciaram o surgimento de personagens femininos, Arlequinas e Pantaleonas que por sua vez causaram uma reviravolta nos roteiros de cenas que foram reformulados surgindo novas histórias, fatos e personagens do con- 
texto local da Amazônia, como o canoeiro, o transexual, a cafetina, o colhedor de açaí e pupunha (frutas típicas da região).
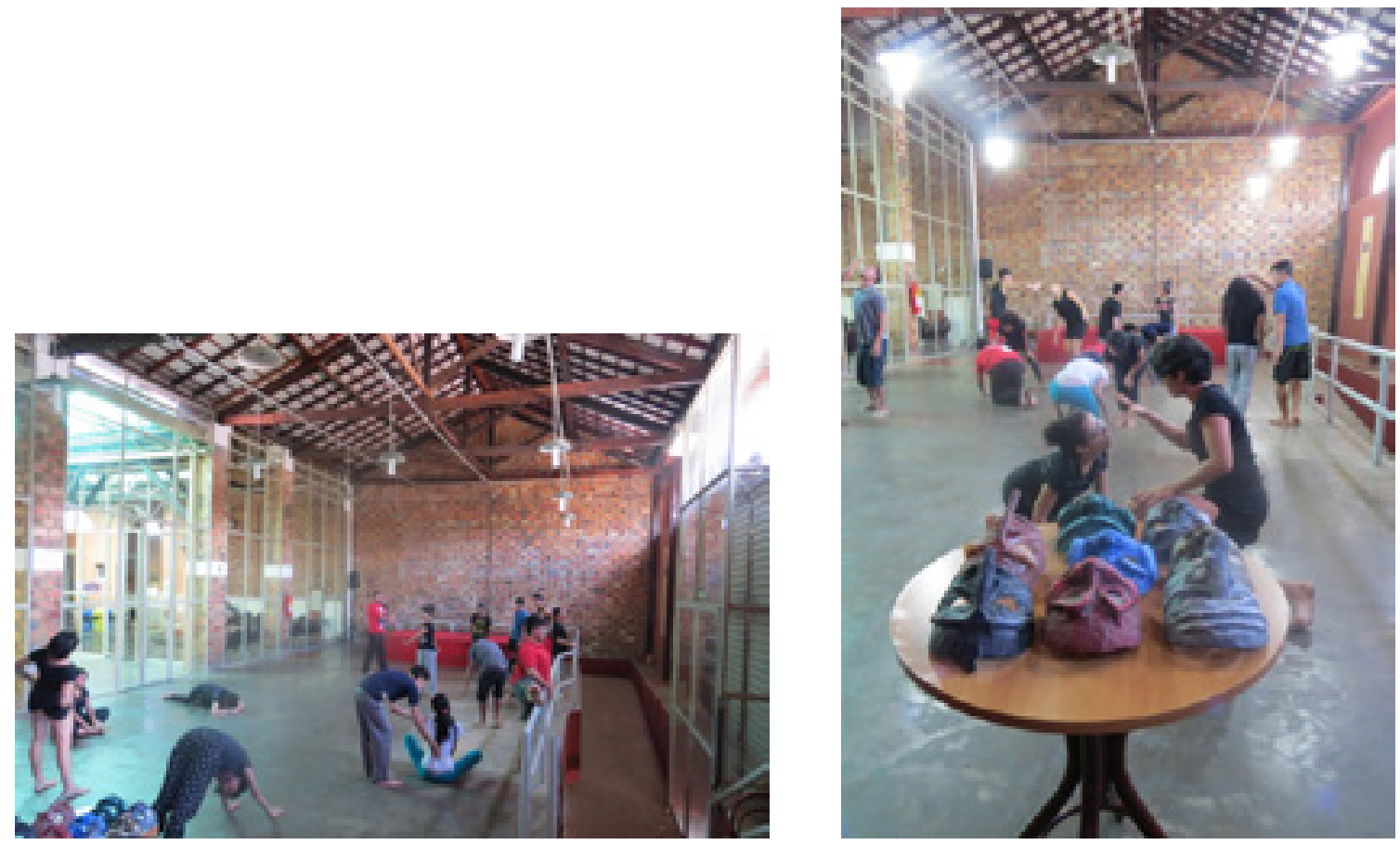

Manaus (AM): Espaço Café-Teatro. Aquecimento individual e em duplas. Fotos: Márcio Silveira (2016)

\section{Encontro de Culturas}

Quero deixar claro que o Manjericão não passou a negligenciar a questão da preparação através de técnicas e treinamento do ator para portar uma máscara. Mantiveram-se as técnicas e formas do trabalho inicial para utilizar uma máscara de commedia dell'arte e o personagem típico a que pertence. A mudança que nos provocou as pesquisas de Miranda e Foucault sobre a "docilização dos corpos" foi que passamos a ter um novo olhar sobre nossas práticas. Levamos em conta a existência das "maquinarias de poder"11 levantadas por Foucault, onde ocorre uma espécie de manipulação demasiada dos gestos e comportamentos dos corpos para determinado fim. Através dos trabalhos práticos anteriormente moldávamos os corpos para o surgimento daqueles personagens específicos que as máscaras já traziam em suas expressões fixas. O que de certa forma impedia no processo das oficinas o desvelamento de outros caminhos de criação por parte dos alunos por onde passávamos.

\footnotetext{
${ }^{11} 0$ momento histórico das disciplinas é o momento em que nasce uma arte do corpo humano, que visa não unicamente o aumento de suas habilidades, nem tampouco aprofundar sua sujeição, mas a formação de uma relação que no mesmo mecanismo o torna tanto mais obediente quanto é mais útil, e inversamente. Forma-se então uma política das coerções que são um trabalho sobre o corpo, uma manipulação calculada de seus elementos, de seus gestos, de seus comportamentos. 0 corpo humano entra numa maquinaria de poder que o esquadrinha, o desarticula e o recompõe. Uma "anatomia política", que é também igualmente uma "mecânica do poder", está nascendo; ela define como se pode ter domínio sobre o corpo dos outros, não simplesmente para que façam o que se quer, mas para que operem como se quer, com as técnicas, segundo a rapidez e a eficácia que se determina. A disciplina fabrica assim corpos submissos e exercitados, corpos "dóceis". (Foucault, 1987, p. 164)
} 


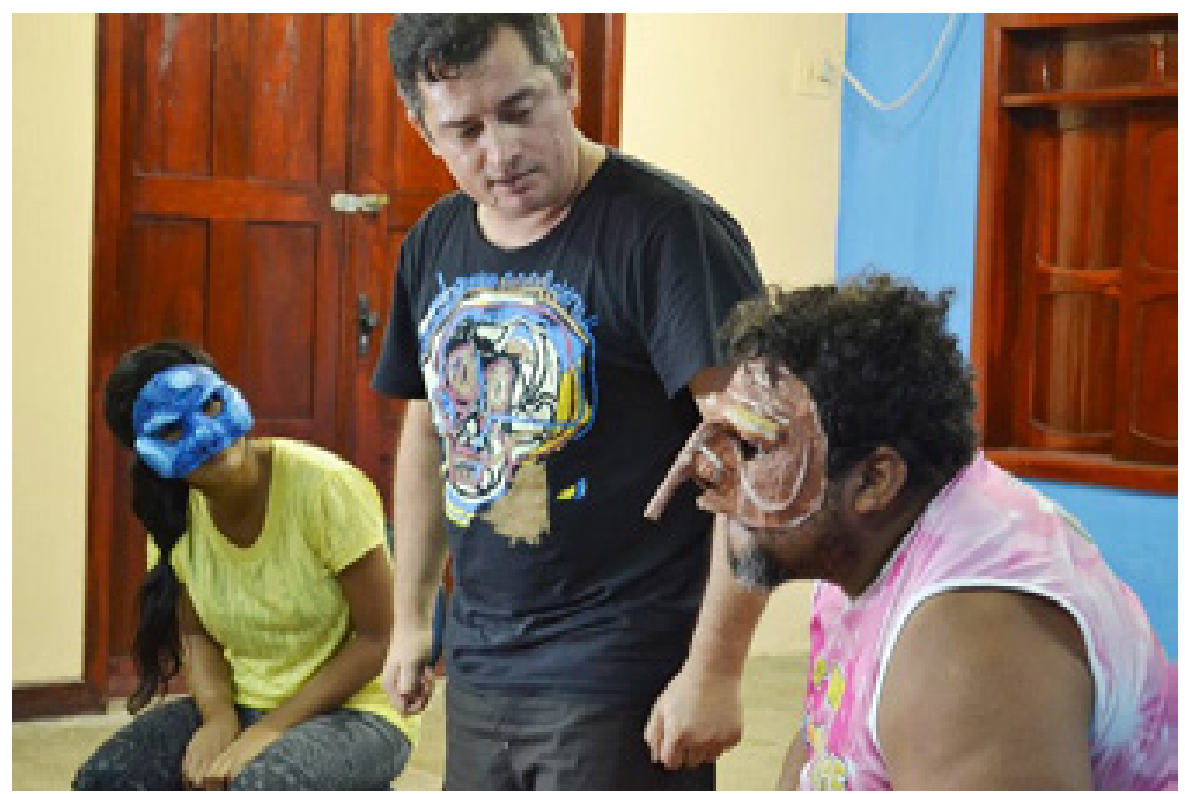

Macapá (AP): Espaço do Conselho Estadual de Cultura. Márcio Silveira acompanha os primeiros contatos com a meia-máscara. Foto: Claudio Silva (2016)

Se nosso trabalho era de conduzir os alunos na construção de dois personagens típicos da commedia dell'arte (Arlequim e Pantaleão) agora, o que podemos chamar de "libertos de uma disciplina rígida", proporcionou o surgimento de novos personagens a partir destas máscaras. Houve um encontro de culturas. Da commedia dell'arte italiana derivaram personagens amazônicos, tipos sociais arraigados ao contexto dos locais onde ocorreram as oficinas. A partir de detalhes históricos semelhantes entre as culturas, como o êxodo territorial, a miséria, a luta de classes, a busca de um lugar ao sol, as cenas foram criadas naturalmente. Um salto da Itália do século XVI para a floresta Amazônica do século XXI.

A origem da commedia dell'arte na Itália do século XVI ocorre num período de grande convergência de cidadãos, num êxodo das pequenas cidades das montanhas italianas que passavam por dificuldades econômicas, em direção às grandes cidades como Veneza e Gênova, que prosperavam muito naquele período. ${ }^{12}$

Estes cidadãos em sua maioria ficavam a margem da sociedade, sobreviviam basicamente como servos em trabalhos de carregadores, entregadores e serviços gerais para os ricos burgueses do período. Esses servos ficaram conhecidos como Zanni ${ }^{13}$, foram os tipos-protótipos que mais tarde desdobraram-se em Arlequins, Briguelas,

\footnotetext{
${ }^{12}$ Dario Fo nos relata que a Itália foi o berço do capitalismo graças ao desenvolvimento das embarcações, "instituição símbolo da cultura renascentista e estandarte da alta burguesia". As famílias mais importantes eram de banqueiros, não sendo por acaso que um Vespúcio ganhou o título de descobridor das Américas, o filho Américo é da mesma família que financiou as três últimas expedições de Cristóvão Colombo, assim "sintomaticamente, a América tem o nome de um banqueiro". Em função das grandes navegações os produtos chegavam à Itália com preços muito baixos, levando assim a falência os camponeses. "Sem conseguir vender os seus produtos, precisavam abandonar suas terras e emigrar em grande quantidade, dirigindo-se para as Repúblicas de Gênova e Veneza. [...]. Eram vinte mil pessoas invadindo Veneza, então uma cidade com uma população pouco superior a cem mil almas. Obviamente, esses desesperados tornaram-se personagens marcantes, modificando todo o ambiente reinante. Fazem explodir uma onde de ressentimento e desprezo, transformando-se em alvo de ironias e gozações, ou até mais do que isso. Viram os bodes expiatórios de todo maus humor, como acontece com todas as minorias indefesas em evidência: falam mal a língua da cidade; praticam toda sorte de disparates; possuem uma fome descomunal e morrem literalmente de fome; suas mulheres aceitam os trabalhos mais humildes e humilhantes, praticando até mesmo a prostituição (o mercado de trabalho de servas já estava saturado)". (Fo, 1998, p. 74-75)

13 "Zanni é uma máscara de origem bergamasca [...] A ocupação típica do Zanni é aquela dos roceiros, habituados a trabalhos pesados: cortar lenha, cavar e colher nabos da terra [...] Zanni tem as mãos cheias de calos enormes, grandes e duros [...] Sendo um tipo do interior, certamente Zanni não é um estúpido, mas também não é muito culto [...] Uma outra característica do Zanni é a sua pobreza crônica: ele é o ponto mais baixo da escala social proposta aos Caracteres da commedia dell'arte. Esta pobreza se manifesta, não somente nas roupas modestas e rasgadas, mas, sobretudo, no apetite do Zanni. A voracidade do Zanni é famosa: ele possui uma enorme fome, que não é somente uma fome biológica, mas uma fome atávica, profunda, de "gerações", uma fome que provém da carência alimentar de seus antepassados, uma fome que (pode-se dizer) Ihe foi passada com o leite materno, uma fome "cromossômica"... e, consequentemente, insaciável". (Contin apud Brondani, 2014, p. 84)
} 
entre outros servos da commedia dell'arte. Já os mais ricos, como o Magnifico, um mercador rico, homem de prestígio típico representante da burguesia que com o passar dos séculos foi ficando velho, sovina, bruto e mesmo com habilidade para negociar ainda sim se enamora fácil e acaba sempre zombado, desta figura típica derivaram além do Pantaleão, uma das principais máscaras da commedia dell'arte, também os Doutores e Capitães. ${ }^{14}$

A partir desta breve retomada histórica do contexto histórico e dos personagens da commedia dell'arte, partimos então para a adaptação de roteiros italianos para o contexto amazônico. Proporcionamos uma abertura para a contextualização local dos personagens, deixando de serem os dois personagens da commedia dell'arte (Pantaleão e arlequim), embora mantendo alguns elementos básicos como fome, sexo, dinheiro e trabalho, não necessariamente nessa ordem.

Relato a seguir duas transposições, uma de cada localidade da região Norte do Brasil que escolhi para este artigo.

Macapá: Cena dos Canoeiros
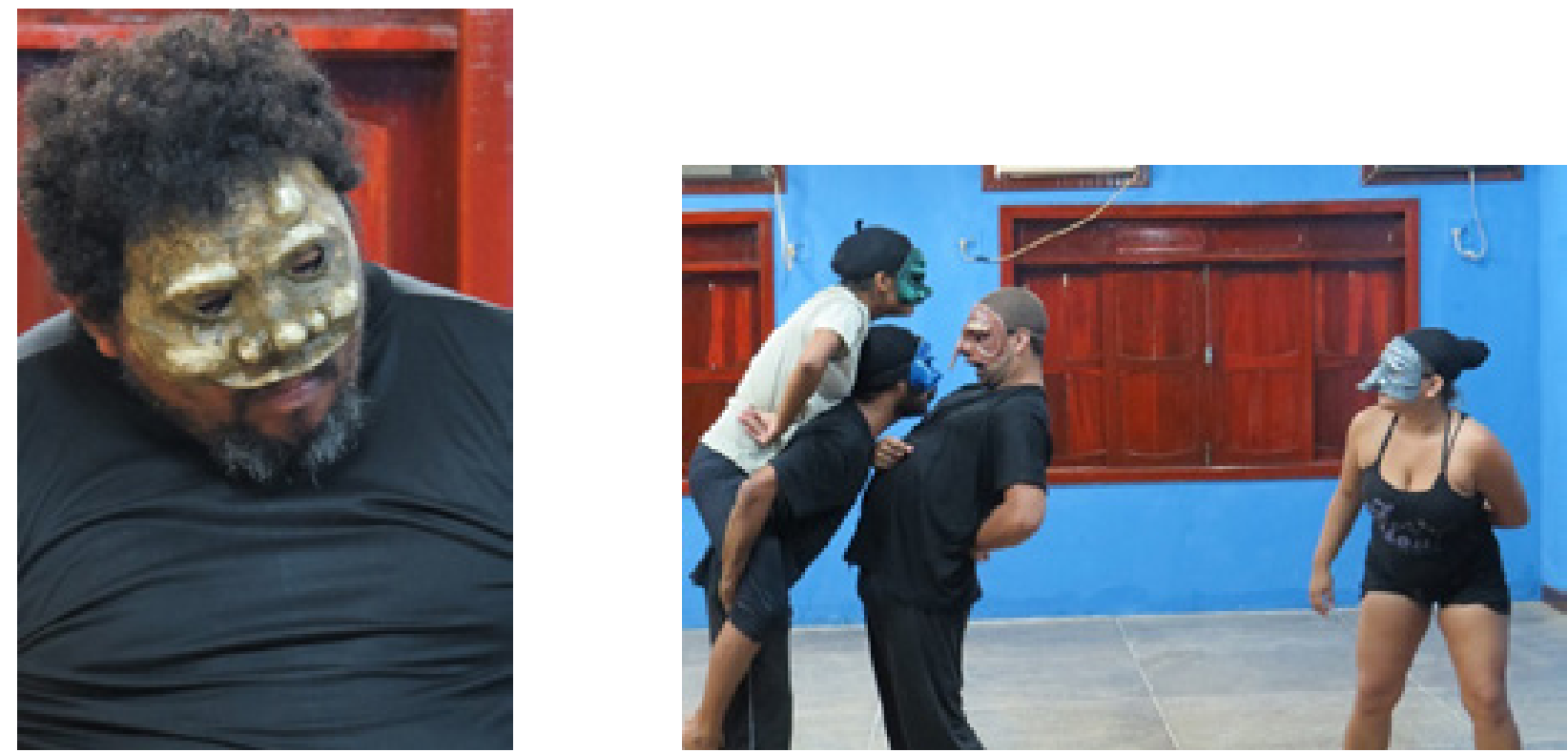

Macapá (AP): À esquerda, o ator George Werner como vendedor de pupunha. À direita, dois canoeiros disputam entre si para convencer a patroa e o patrão para o trabalho na travessia de um rio. Fotos: Márcio Silveira (2016).

O roteiro inicial consistia na chegada de um velho Pantaleão na cidade onde crescera e desde a adolescência não voltara. Agora rico, com uma mala de dinheiro, seu único desejo era mostrar a todos que havia prosperado e se ainda fosse possível desejava retomar o enlace com uma antiga namorada. Encontra um Arlequim que lhe serve para todos os ocorridos em dois dias na cidade. No final Arlequim descobre que o velho sovina não tem mais riqueza alguma.

Como roteiro adaptado propomos conjuntamente com os alunos o seguinte: Pantaleão chega de um lado do rio e precisa atravessar para chegar acidade de sua

\footnotetext{
14 "As máscaras da commedia dell'arte representam e satirizam as principais componentes da sociedade italiana da época, e os diversos dialetos ou falas com expressões dialetais refletem essa "atualidade" que há de ter sido central para o efeito cômico junto ao público". (Scala; Barni, 2003, p. 22)
} 
infância. Para isso encontra dois canoeiros transportadores de açaí e pupunha que passam a disputar entre si quem irá leva o novo possível patrão. Com seus trejeitos e linguajares típicos do Amapá decidem que um leva a mala e outro o patrão, segue-se mais uma disputa verbal e corporal para ver quem leva o patrão, pois assim o vencedor poderia servir por dois dias o patrão, ganhando assim muito dinheiro. Após a travessia, Pantaleão decide ter dois empregados. Logo Pantaleão encontra uma velha amiga, uma Pantaleona, que talvez seja sua amada juvenil. Aos poucos ela se aproxima dos dois servos que juntos planejam dar um golpe no velho rico. Os alunos são estimulados a usar e abusar do linguajar típico das ruas e do cais. Após muitos quiproquós ${ }^{15}$, descobrem que o velho na verdade é miserável e que lhes aplicou um golpe, deixando a mala com trapos sujos e levando uma canoa com todo o açaí e pupunha. Frutas que em determinadas épocas são fonte de renda de muitas pessoas e uma forte moeda de troca na Amazônia.

Manaus: Cena do baixo-meretrício.

O roteiro inicial consistia no período de uma noite na vida de um patrão e empregado. Dia de sexo. O patrão desejando muito sexo manda seu empregado buscar uma bebida forte pra beber antes de ir a uma boate fazer sexo. De posse das moedas o empregado traz urina para o patrão que bebe e fica muito excitado querendo transar com qualquer pessoa que chegue na sua frente. Arlequim foge, depois retorna com outro servo, ambos levam o patrão numa boate. Também desejam que o patrão pague para eles fazerem sexo a vontade na boate, o que não conseguem. Após muitos desentendimentos e correrias, os três levam uma surra porque Arlequim fez artimanhas colocando a tal urina nas bebidas de todos.
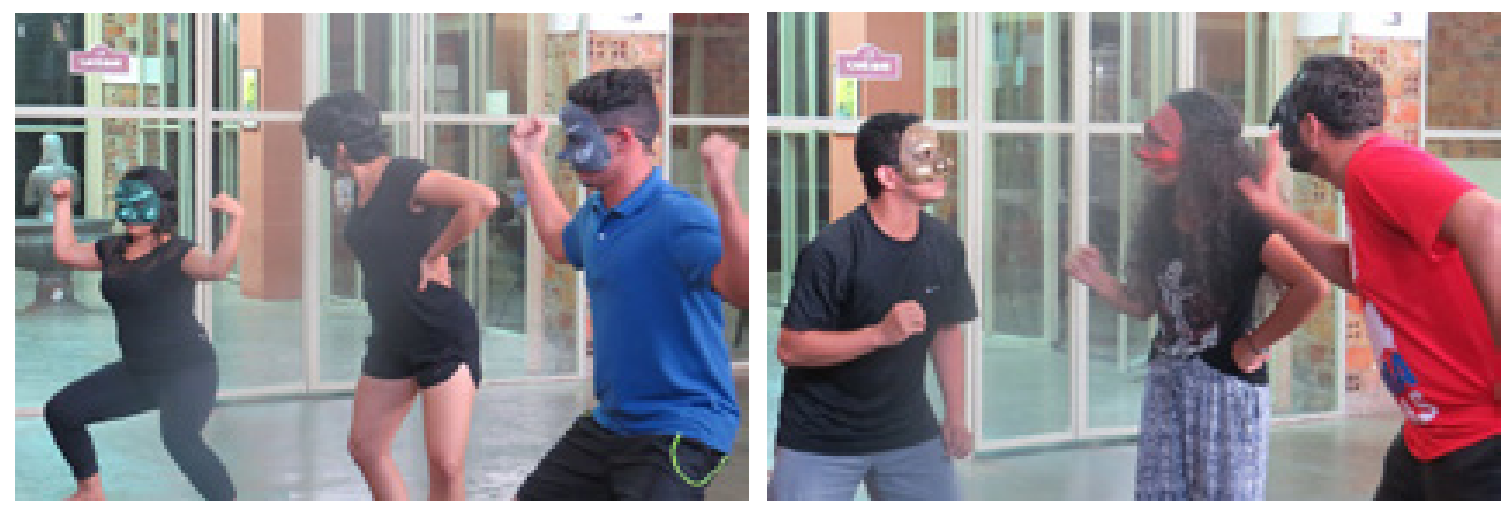

Manaus (AM): Duas cenas onde há uma patroa para dois Arlequins em busca de emprego de guia do local. Fotos: Márcio Silveira (2016)

Como roteiro adaptado - a oficina ocorreu num espaço cultural localizado na parte histórica e abandonada de Manaus, que na sua fundação o bairro era conhecido pelos mais suntuosos cabarés, frequentados pelos coronéis da extração da borracha (o ouro negro) que era exportada para o mundo todo. Hoje parte do bairro é conhecida como zona do meretrício e de traficantes. Cientes deste contexto, criamos

\footnotetext{
17 "Do latim quid pro quo: isto por aquilo. Recurso, em geral cômico, através do qual as personagens, por problemas de comunicação, interpretam erradamente o sentido dos diálogos ou o comportamento de outras personagens. Esses problemas de comunicação podem decorrer de ignorância, de deficiência auditiva, de redação deficiente ou por quaisquer outros motivos". (Guinsburg, 2006, p. 257)
} 
conjuntamente o seguinte: Diante do desejo do patrão de algo que o esquente para ir às boates, Arlequim lhe dá dois comprimidos de Viagra. No caminho para a boate surge um grupo de transexuais que os levam para dar uma passeada pelas boates da beiro do rio. Já perto do final da noite a última boate era uma espécie de igreja abandonada, cuja Patroa era um travesti chamado por todos de "Madre". Após muitos quiproquós, no clarear do dia, Pantaleão sai da "igreja-boate" recém-casado com a "Madre". No final há um grande cortejo com todas as máscaras-personagens junto ao novo casal da cidade.

\section{Dócil e indócil}

Nesta busca por uma mudança e melhor entendimento sobre o controle e docilização dos corpos, pudemos também compreender o quanto é necessário um corpo "indócil" nas oficinas de meia-máscara. "indócil" no sentido de um corpo não totalmente regrado sobre como usar uma meia-máscara de commedia dell'arte, que não esteja dentro de uma rigidez de partituras de movimentos e modulação de vozes. Passamos a encontrar um corpo mais vivo-ativo e comunicativo. Um corpo que vai além de "uma espécie de moldura à máscara que transforma sua fixidez". (Fo, 1998, p. 53).

Por outro lado, também nos sentimos menos "engessados" e "controladores". Mudamos os procedimentos em boa porcentagem das oficinas e pudemos notar 0 surgimento de novas possibilidades de jogo com a meia-máscara, bem como a atividade tornou-se mais libertária e as cenas mais potentes.

\section{Referências}

BARBA, Eugênio. A Canoa de Papel: tratado de antropologia teatral. São Paulo: Hucitec/UNICAMP, 1994.

; SAVARESE, Nicola. A Arte Secreta do Ator: dicionário de antropologia teatral. São Paulo: Hucitec/UNICAMP, 1995.

BRONDANI, Joice Aglae. Varda Che Baucco! Transcursos fluviais de uma pesquisatriz: Bufão, commedia dell'arte e manifestações espetaculares populares brasileiras. Salvador: Fast Design, 2014.

BROOK, Peter. O Ponto de Mudança: quarenta anos de experiências teatrais: 19461987. Rio de Janeiro: Civilização Brasileira, 1994.

COPEAU, Jacques. Apelos. 2013. [Trad./Apres. José Ronaldo FALEIRO]. SP: Perspectiva, 2013.

COSTA, Felisberto Sabino da. A Máscara e a formação do ator. In: Móin-Móin Revista de Estudos sobre Teatro de Formas Animadas. Jaraguá do Sul: SCAR/UDESC, ano 1, v. 1. p. $25-51,2005$. 
FO, Dario. RAME, Franca (Org.). Manual Mínimo do Ator. São Paulo: SENAC, 1998.

FOUCAULT, Michel. Vigiar e Punir: história da violência nas prisões. Petrópolis: Vozes, 1987.

GUINSBURG, J.; FARIA, J. R.; LIMA, M. A. (Org.). Dicionário de teatro brasileiro: temas, formas e conceitos. São Paulo: Perspectiva: SESC São Paulo, 2006.

MIRANDA, Maria Brígida de. Playful Training: towards capoeira in the physical training of actors. 2003. Tese. (Doutorado em Filosofia, Teatro e Drama) - School of Comunications, Arts and Critical Enquiry, Faculty of Humanities and Social Sciences, La Trobe University, Melbourne, 2003.

PAVIS, Patrice. Dicionário de teatro. 3. ed. - São Paulo: Perspectiva, 2008.

SCALA, Flaminio; BARNI, Roberta (Organização, tradução, introdução e notas.). $A$ Loucura de Isabella e outras Comédias da commedia dell'arte. São Paulo: Iluminuras, 2003.

TELLES, Narciso. Pedagogia do Teatro e o teatro de rua. Porto Alegre: Mediação, 2008.

Recebido em: 30/04/2017 Aprovado em: 18/11/2017 